\title{
Major stroke in a 19-year-old patient with a univentricular heart
}

\author{
This article was published in the following Dove Press journal: \\ International Journal of General Medicine \\ 8 January 2013 \\ Number of times this article has been viewed
}

\author{
Mads Riemann ${ }^{1,2}$ \\ Lars Idorn ${ }^{3}$ \\ Aase Wagner ${ }^{4}$ \\ Lars Søndergaard ${ }^{3}$ \\ Jørgen K Kanters ${ }^{1,2}$ \\ 'Department of Internal Medicine, \\ Elsinore Hospital, Elsinore, Denmark; \\ ${ }^{2}$ Department of Biomedical \\ Sciences, University of Copenhagen, \\ Copenhagen, Denmark; ${ }^{3}$ Department \\ of Cardiology, Copenhagen University \\ Hospital, Section 20I4, Rigshospitalet, \\ Copenhagen, Denmark; ${ }^{4}$ Department \\ of Radiology, Copenhagen University \\ Hospital, Section 3023, Rigshospitalet, \\ Copenhagen, Denmark
}

\begin{abstract}
Patients with univentricular heart malformations are at increased risk of suffering from thromboembolic events. We present a case of a 19-year-old woman born with a univentricular heart who suffered a major stroke while being treated with only salicylic acid. At least $20 \%$ of patients with univentricular hearts have been reported to experience thromboembolic events, of which $25 \%$ are fatal. Despite the high incidence of thromboembolic events, no consensus has been reached regarding the role of long-term anti-thrombotic treatment in this group of patients. This lack of consensus warrants future studies that compare the different therapeutic strategies.
\end{abstract}

Keywords: univentricle, stroke, antithrombotic treatment

\section{Introduction}

Patients with univentricular heart malformations are at increased risk of suffering from thromboembolic events (TE). At least $20 \%$ of patients with univentricular hearts have reported to experience TE, of which $25 \%$ are fatal. Despite the high incidence of TE, no consensus has been reached regarding the role of long-term anti-thrombotic treatment in this group of patients. Here, we present a case of a 19-year-old woman with a univentricular heart who suffered a major stroke.

\section{Case}

A 19-year-old woman born with a univentricular heart was found unconscious in her bed in the morning. She was respiratory and circulatory stable with no fever at admission to the local hospital. The Glasgow Coma Scale score was 5 (eyes, 1; verbal, 1; motor, 3). Pupils were of normal size and contracted normally to light stimulus. An electrocardiogram showed sinus rhythm, left axis deviation, and left-sided hypertrophy, but was otherwise normal. The patient's only medication was $75 \mathrm{mg}$ of salicylic acid once a day.

The toxicological urine screen was normal. A test of arterial blood gasses revealed a fully compensated metabolic acidosis with $\mathrm{pH} 7.37$ (normal range 7.37-7.45) and base excess $-7.7 \mathrm{mM}(-3.0$ to $3.0 \mathrm{mM})$. Venous blood tests showed raised plasma lactate $3.7 \mathrm{mM}(0.7-2.1 \mathrm{mM})$, plasma myoglobin $280 \mu \mathrm{g} / \mathrm{L}(19-49 \mu \mathrm{g} / \mathrm{L})$, plasma glucose $8.6 \mathrm{mM}(4.2-7.2 \mathrm{mM})$, plasma fibrin D-dimer $1.0 \mathrm{mg} / \mathrm{L}(0.0-0.5 \mathrm{mg} / \mathrm{L})$, and INR $1.5(<1.2)$, whereas the remaining standard tests were all normal, including hemoglobin, leucocyte differential count, electrolytes, $C$ reactive protein, liver and pancreas enzymes, renal parameters, plasma ethanol, plasma paracetamol, and plasma salicylate.
Correspondence: Mads Riemann Department of Biomedical Sciences, University of Copenhagen, 3C Blegdamsvej, 10.5, 2200 Copenhagen N, Denmark

Tel +4535327519

Fax +45 35327418

Email riemann@sund.ku.dk 
Shortly after admission, the patient developed Babinski reflexes and a pronounced decorticate posture with spontaneous flexion of the arms over the chest and extended legs with feet turned inward. Cranial X-ray computed tomography and lumbar puncture were both normal. After a tracheal tube was inserted and assisted ventilation was initiated, the patient was transferred to the neurological intensive care unit at a tertiary hospital. A repeated computed tomography scan and magnetic resonance imaging of the head were performed, as well as a computed tomography angiography of the head and the neck. These scans unveiled a major stroke located in the left cerebral (Figure 1) and cerebellar hemispheres, corresponding to the areas supplied by the left middle and posterior cerebral arteries and the left superior cerebellar artery. The left side of pons was also affected (Figure 2). A segmental occlusion in the top of the basilar artery was identified (Figure 3). Carotid and vertebral arteries were normal bilaterally. Finally, a transthoracic echocardiography was performed, revealing a well-functioning univentricular heart with no detectable thrombi. Warfarin was prescribed and the patient gradually regained consciousness. However, a severe right-sided hemiparesis persisted and the patient was transferred to a local neurorehabilitation unit. Later, a magnetic resonance imaging scan of the thorax and upper abdomen was

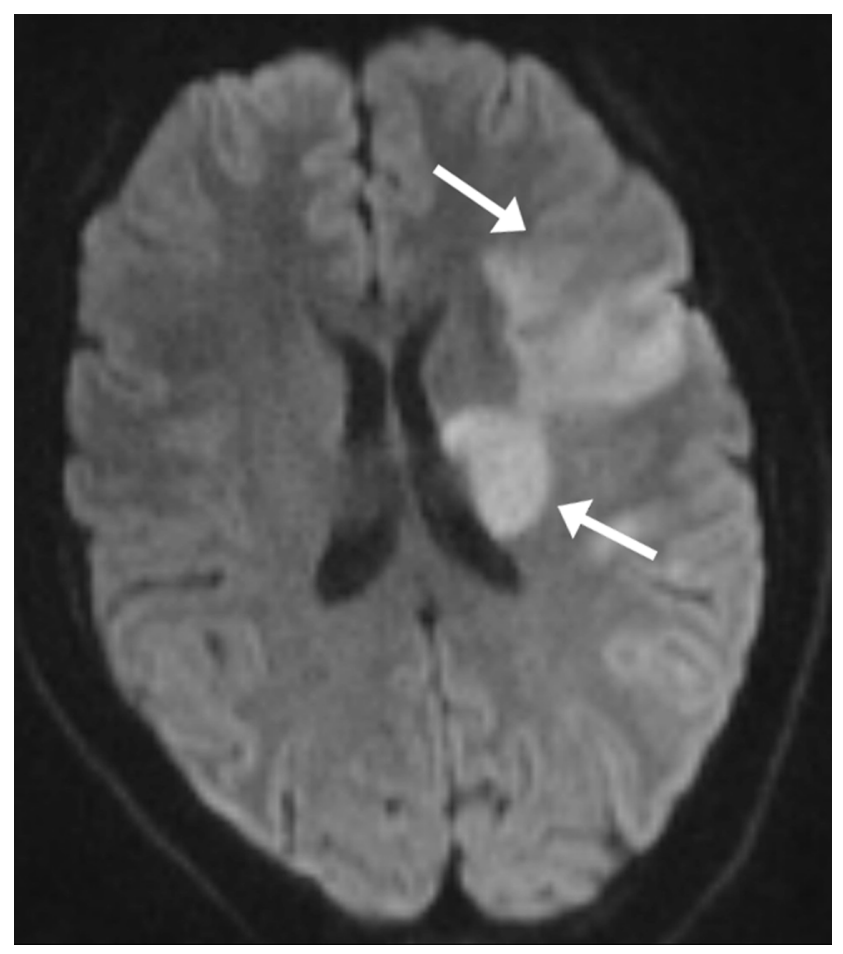

Figure I Magnetic resonance imaging. Diffusion weighted image showing infarcts in the left cerebral hemisphere (arrows).

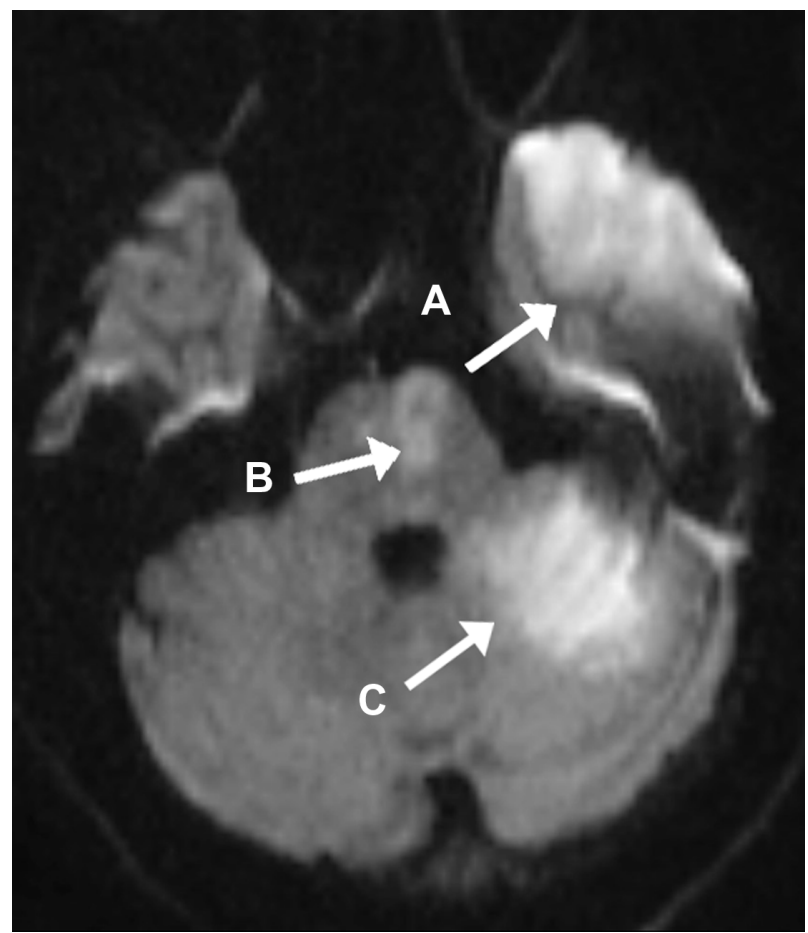

Figure 2 Magnetic resonance imaging. Diffusion weighted image showing infarcts in the left temporal pole (A), pons (B), and the left cerebellar hemisphere (C).

performed (Figure 4). This scan showed a univentricular malformation without visible thrombi.

The patient had been referred to a cardiologist at the age of 5 months due to shortness of breath and failure to thrive. Cardiac ultrasound and catheterization had revealed a double

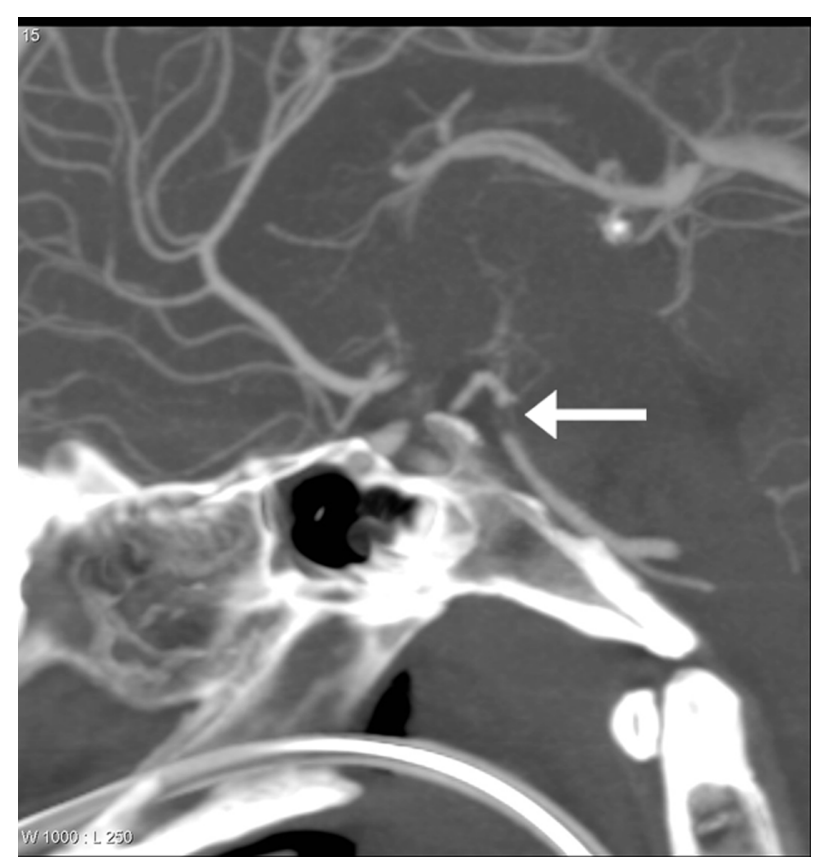

Figure 3 Computed tomography angiography. 2D sagittal reconstructed image showing thrombus in the distal part (top) of the basilar artery (arrow). 


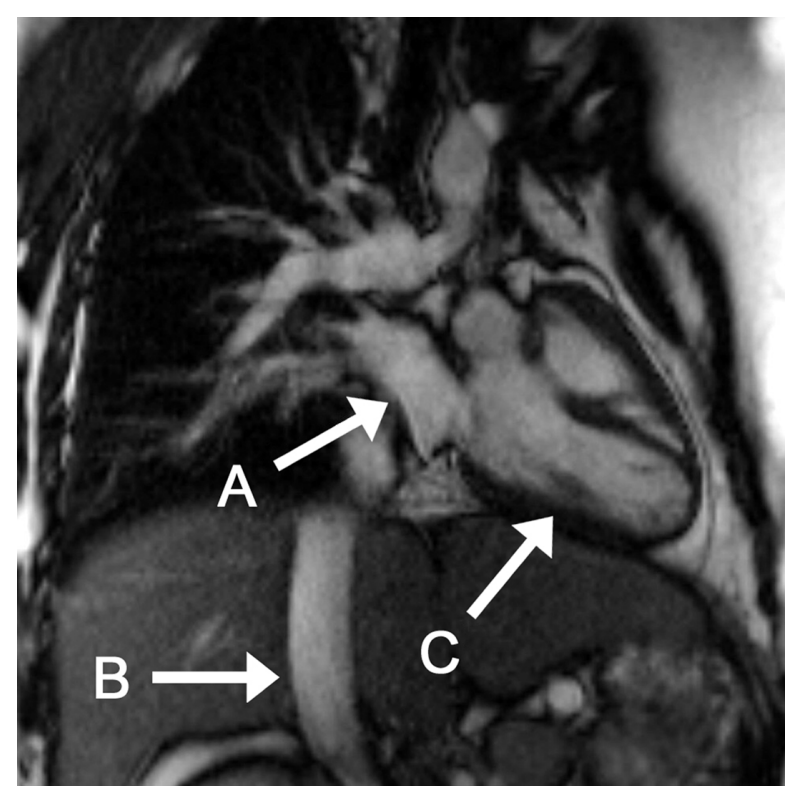

Figure 4 Magnetic resonance imaging scan in the frontal plane showing the thorax and upper abdomen of the patient. (A) Fontan tunnel connecting the superior and inferior venae cava with pulmonary circulation. (B) The inferior vena cava going through the liver. (C) The univentricle without visible thrombi.

inlet left ventricle (Figure 5) and a hypoplastic right ventricle without transposition of the great arteries. Symptoms were caused by heart failure due to high pulmonary flow, which was treated by pulmonary artery banding. At the age of 6 years, a total cavopulmonary connection (TCPC), including

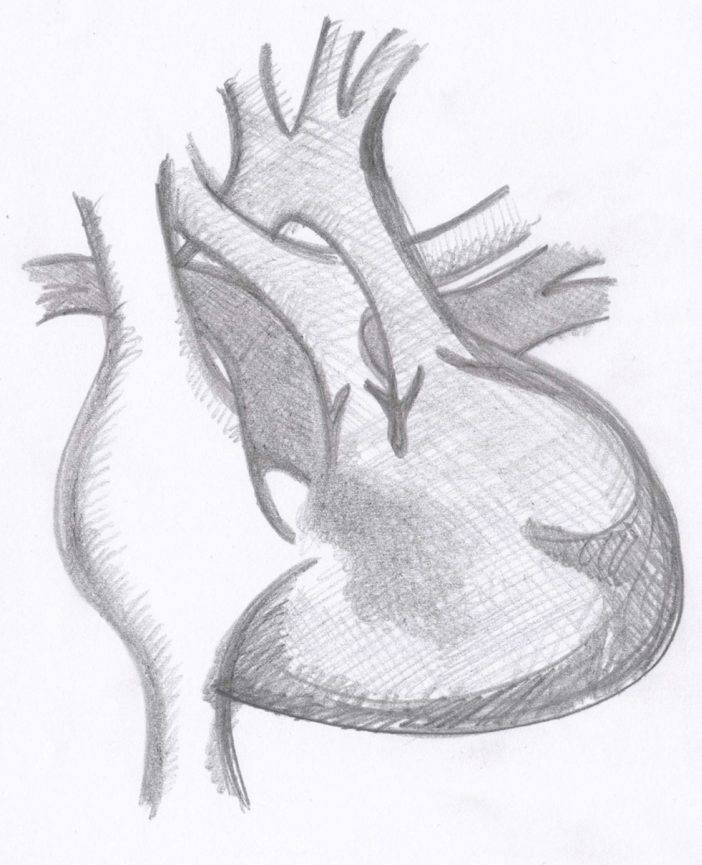

Figure $\mathbf{5}$ Schematic illustration of a heart with double inlet left ventricle. a lateral tunnel with fenestration to the right atrium, was established. The surgical procedure markedly improved the patient's well-being, and, at the age of 13 years, the fenestration was closed. Life-long prophylactic antithrombotic treatment with salicylic acid was prescribed. During the last surgical intervention, the patient suffered mild brain damage and was now described as behaving at the level of a 12-year-old. The patient had no history of cardiac arrhythmias or enlarged atria. Postoperative echocardiography revealed good systolic function of the left ventricle and mild right atrioventricular valve regurgitation.

\section{Discussion}

Since no cardiac thrombi were identified, it is not known whether the described stroke was caused by a cardiac-derived embolus or spontaneous cranial thrombi. Spontaneous thrombi in 19-year old patients are, however, extremely rare. Hence, seen in the light of a known cardiac malformation, the probability of a cardiac-derived cerebral embolus is very high.

The incidence of univentricular hearts is reported to be between 0.5 and three cases per 10,000 live births. ${ }^{1}$ Today, patients with univentricular heart conditions are usually treated surgically with a three-stage TCPC/Fontan procedure, ${ }^{2}$ which separates the systemic and pulmonary venous return - a precondition for adequate oxygenation of the arterial blood entering systemic circulation. TCPC provides passive pulmonary blood flow without a rightsided ventricular pumping chamber. The technique has evolved from the classic Fontan ${ }^{3}$ (right atrium-to-pulmonary artery connection) through an intracardiac lateral tunnel procedure, and it is currently performed in many centers as an extracardiac tunnel procedure by insertion of a tube graft between the inferior vena cava and the pulmonary artery. ${ }^{4}$

$\mathrm{TE}$, both systemic venous and arterial, are a major cause of early and late mortality in TCPC patients. The reported incidence of TE in these patients varies from $3 \%$ to $25 \%$, depending on study design, imaging technique, and follow-up period duration. Studies with longer follow-up periods and more sensitive imaging studies suggest an incidence of at least $20 \%$, of which the mortality rate is $25 \% .^{5-9}$ Asymptomatic pulmonary emboli have been detected in $16 \%$ of TCPC patients. Although the etiology for the high risk of TE is not well defined, possible explanations include abnormal blood flow in the univentricle, arrhythmias, venostasis, dehydration, protein-losing enteropathy, and coagulation abnormalities. No stratification of TE risk has been made between the different types of surgical intervention. Such data would be 
very useful and should be compared against the efficacy of each treatment.

Fontan circulation has been reported to be associated with hemostatic abnormalities. Procoagulant factors (factors II, V, VII, IX, and X; plasminogen; and fibrinogen) and anticoagulant factors (protein $\mathrm{C}$ and antithrombin III) are lower than normal controls prior to stage two or three of TCPC completion. ${ }^{10,11}$ Increased platelet reactivity prior to TCPC completion has also been shown. A recent report, however, found no significant differences in thromboelastography (a global whole-blood assay of coagulation) in pediatric TCPC patients compared with healthy children. ${ }^{12}$

Despite the high incidence of TE, no consensus has been reached about the role of long-term antiplatelet or anticoagulation therapy in those patients who remain in stable sinus rhythm. Some studies advise against routine anticoagulation, ${ }^{13}$ whereas others recommend routine antiplatelet ${ }^{14}$ or anticoagulation therapy. ${ }^{15,16}$ One recent study suggests that antiplatelet and anticoagulation therapy are equally effective in preventing TE. ${ }^{17}$ TE reduce quality of life ${ }^{18}$ and cause sudden death ${ }^{19}$ in adult patients with Fontan circulation. Therefore, in these patients, the benefit of long-term prophylactic antiplatelet or anticoagulation therapy must be carefully considered and weighed against the risk of detrimental hemorrhagic side effects.

Disagreement about antithrombotic therapy in TCPC patients warrants future study that compares the different therapeutic strategies. Future studies should most likely be observational case-control studies due to the practical and ethical problems associated with randomized controlled trials. The need for such studies is emphasized by the presented case, which might suggest that more aggressive antithrombotic strategies should be routinely introduced.

\section{Acknowledgments}

This study was supported by grants from the Danish Council for Strategic Research and the Fraenkel Foundation. We thank Benedikte Achen for drawing the schematic illustration of the univentricular heart in Figure 5.

\section{Disclosure}

The authors report no conflicts of interest in this work.

International Journal of General Medicine

\section{Publish your work in this journal}

The International Journal of General Medicine is an international, peer-reviewed open-access journal that focuses on general and internal medicine, pathogenesis, epidemiology, diagnosis, monitoring and treatment protocols. The journal is characterized by the rapid reporting of reviews, original research and clinical studies across all disease areas.

\section{References}

1. Khairy P, Poirier N, Mercier LA. Univentricular heart. Circulation. 2007;115:800-812.

2. Kaulitz R, Hofbeck M. Current treatment and prognosis in children with functionally univentricular hearts. Arch Dis Child. 2005;90:757-762.

3. Fontan F, Baudet E. Surgical repair of tricuspid atresia. Thorax. 1971;26: 240-248.

4. d'Udekem Y, Iyengar AJ, Cochrane AD, et al. The Fontan procedure: contemporary techniques have improved long-term outcomes. Circulation. 2007;116:I157-I164.

5. Kaulitz R, Luhmer I, Bergmann F, Rodeck B, Hausdorf G. Sequelae after modified Fontan operation: postoperative haemodynamic data and organ function. Heart. 1997;78:159-159.

6. Monagle P, Cochrane A, McCrindle B, Benson L, Williams W, Andrew M. Thromboembolic complications after fontan procedures - the role of prophylactic anticoagulation. J Thorac Cardiovasc Surg. 1998;115: 493-498.

7. Rosenthal DN, Friedman AH, Kleinman CS, Kopf GS, Rosenfeld LE, Hellenbrand WE. Thromboembolic complications after Fontan operations. Circulation. 1995;92(9 Suppl):II287-II293.

8. Idorn L, Jensen AS, Juul K, et al. Thromboembolic complications in Fontan patients: population-based prevalence and exploration of the etiology. Pediatr Cardiol. Epub 2012 Jul 28.

9. Idorn L, Olsen M, Jensen AS, et al. Univentricular hears in Denmark 1977 to 2009: incidence and survival. Int J Cardiol. Epub 2012 Apr 20.

10. Odegard KC, McGowan FX Jr, DiNardo JA, et al. Coagulation abnormalities in patients with single-ventricle physiology precede the Fontan procedure. J Thorac Cardiovasc Surg. 2002;123:459-465.

11. Odegard KC, McGowan FX Jr, Zurakowski D, et al. Coagulation factor abnormalities in patients with single-ventricle physiology immediately prior to the Fontan procedure. Ann Thorac Surg. 2002;73: 1770-1777.

12. Raffini L, Schwed A, Zheng XL, et al. Thromboelastography of patients after fontan compared with healthy children. Pediatr Cardiol. 2009;30: 771-776.

13. Barker PC, Nowak C, King K, Mosca RS, Bove EL, Goldberg CS. Risk factors for cerebrovascular events following fontan palliation in patients with a functional single ventricle. Am J Cardiol. 2005;96: 587-591.

14. Seipelt RG, Franke A, Vazquez-Jimenez JF, et al. Thromboembolic complications after Fontan procedures: comparison of different therapeutic approaches. Ann Thorac Surg. 2002;74:556-562.

15. Kaulitz R, Ziemer G, Rauch R, et al. Prophylaxis of thromboembolic complications after the Fontan operation (total cavopulmonary anastomosis). J Thorac Cardiovasc Surg. 2005;129:569-575.

16. Mahnke CB, Boyle GJ, Janosky JE, Siewers RD, Pigula FA. Anticoagulation and incidence of late cerebrovascular accidents following the Fontan procedure. Pediatr Cardiol. 2005;26:56-61.

17. Marrone C, Galasso G, Piccolo R, et al. Antiplatelet versus anticoagulation therapy after extracardiac conduit fontan: a systematic review and meta-analysis. Pediatr Cardiol. 2011;32:32-39.

18. van den Bosch AE, Roos-Hesselink JW, Van DR, Bogers AJ, Simoons ML, Meijboom FJ. Long-term outcome and quality of life in adult patients after the Fontan operation. Am J Cardiol. 2004;93:1141-1145.

19. Khairy P, Fernandes SM, Mayer JE Jr, et al. Long-term survival, modes of death, and predictors of mortality in patients with Fontan surgery. Circulation. 2008;117:85-92.

\section{Dovepress}

A key focus is the elucidation of disease processes and management protocols resulting in improved outcomes for the patient. The manuscript management system is completely online and includes a very quick and fair peer-review system. Visit http://www.dovepress.com/ testimonials.php to read real quotes from published authors. 